\title{
Susceptibility of Anopheles Mosquitoes to Deltamethrin and Bendiocarb Insecticides in Nasarawa Local Government Area, Nasarawa State Nigeria
}

\author{
P.S. Lama, J. D. C. Tongjura, R. J. Ombugadu, and A. B. Yako
}

\section{ABSTRACT}

\begin{abstract}
Anopheles mosquito's resistance to insecticides has been one of the major challenges in eradicating malaria. This study was carried out to determine the susceptibility status of Anopheles mosquitoes to Deltamethrin and Bendiocarb in some communities of Nasarawa Local Government Area of Nasarawa State for four months. The research was carried out at the insectary laboratory of Nasarawa State University Keffi. Center for Disease Control (CDC) bioassay bottle and WHO impregnated papers were used to test the susceptibility of Anopheles mosquitoes. The result shows that Anopheles mosquitoes exposed to Bendiocarb and Deltamethrin using CDC bioassay bottles were susceptible at $15 \mathrm{mins}$, there was no mortality recorded from the control at 30 minutes of exposure. Anopheles mosquitoes exposed to WHO impregnated paper of Bendiocarb and Deltamethrin were susceptible at 60 minutes, mortality was recorded at $24 \mathrm{~h}$ post exposure time from the control. $\chi^{2}$ analysis of Bendiocarb and Deltamethrin insecticides exposed to CDC bioassay bottles was statistically insignificant $p>0.05$, while $\chi^{2}$ analysis of Bendiocarb and Deltamethrin exposed to WHO impregnated papers was also insignificant $\mathbf{p}>0.05$. These results indicated susceptibility of Anopheles mosquitoes to Bendiocarb and Deltamethrin for the two methods of susceptibility test. The use of these synthetic insecticides in the control of malaria should be encouraged and made available.
\end{abstract}

Keywords: Anopheles mosquitoes, Bendiocarb, Bioassay, Deltamethrin.
Published Online: June 12, 2021

ISSN: 2684-5199

DOI: $10.24018 /$ ejbio.2021.2.3.202

P. S. Lama*

Faculty of Natural and Applied Sciences, Department of Zoology, Nasarawa State University Keffi, Nasarawa State Nigeria.

(e-mail: patiencesunday213@gmail.com) J. D. C. Tongjura

Faculty of Natural and Applied Sciences, Department of Zoology, Nasarawa State University Keffi, Nasarawa State Nigeria.

(e-mail: jctonjura@ ${ }^{@ m a i l . c o m) ~}$ R. J. Ombugadu

Faculty of Natural and Applied Sciences, Department of Zoology, Nasarawa State University Keffi, Nasarawa State Nigeria.

(e-mail: ruthombugadu@gmail.com) A. B. Yako

Faculty of Natural and Applied

Sciences, Department of Zoology,

Nasarawa State University Keffi,

Nasarawa State Nigeria.

(e-mail: 66yako@gmail.com)

*Corresponding Author

\section{INTRODUCTION}

The general use of insecticides for agricultural pests, human vector and livestock diseases has make insecticides resistance difficult in the control of malaria [19]. These mosquitoes transmit human diseases such as malaria, yellow fever, dengue fever, hemorrhagic fever, filariasis and encephalitis [17], [12]. These have account for high incidence of maternal and mortality rate, financial losses in the treatment and prevention of malaria to about 132 billion naira in Nigeria [7]. Nigeria and public health agencies responsible for public health in Nigeria have set up a control program to eradicate the disease. The malaria vector intervention control program in Nigeria focuses more on Long Lasting Insecticide Nets (LLIN), Indoor Residual Spray (IRS), intermittent preventive treatment (IPT) and environmental management [14]. Despite all these intervention control, malaria has remained one of the major challenges in the world despite an intense national and international efforts [23] However, attention should be given to malaria control in both rural and urban communities to aimed at determining the susceptibility of Anopheles mosquitoes to Deltamethrin and Bendiocarb insecticide.

Resistance of Anopheles mosquitoes to insecticides in Nigeria is on the increase and these has shown that Anopheles gambiae s. $s$ is resistance to DDT and less to Permethrin in all the geographical zones of Nigeria, but highest levels of resistance were found in the forest savannah, Mosaic and Guinea savanna. For instance, Anopheles mosquitoes were resistance to all the classes of insecticides except organophosphate in Ghana while DDT and Permethrin showed high levels of resistance in Cameroun and Ogun state, Nigeria [4], [5], [22], [2]. In Auyoof Jigawa state, susceptibility status of Anopheles species siblings to three classes of insecticides such as DDT, Permethrin and Bendiocarb using WHO adult insecticides susceptibility bioassay was observed. The Anopheles. gambiae were highly resistant to DDT and Permethrin but less resistant to Bendiocarb [8].

In Awka Anambra state, Anopheles mosquitoes were exposed to the three classes of insecticide i.e., 
Organochlorine, Pyrethroid and Carbamate. It was observed that Anopheles mosquitoes were susceptible to Carbamate (Bendiocarb) and resistant to the other classes of insecticide (Pyrethroid and Organochlorine) [15], [9] in Rwanda. It was also observed by [18] that Anopheles mosquitoes were susceptible to the four insecticides in Akwa Ibom state such as Deltamethrin, Lambdacyhalothrin, Permithrin and Malathion. Three species of Anopheles mosquitoes, An. gambiae, An. aranbiasis and An. Melas were exposed to Deltamethrin, DDT and Propoxur in Gambia, by [11] observed that the mosquitoes were susceptible except for An. gambiae which was resistant to DDT.

\section{MATERIALS AND METHODS}

\section{A. Study Area}

The study was carried out in Nasarawa Local Government Area of Nasarawa state which is located in the western senatorial zone with latitude $08^{\circ} 41^{\prime} 20^{\prime \prime}$ to $08^{\circ} 32^{\prime} 10^{\prime \prime} \mathrm{N}$ and longitude $07^{\circ} 48^{\prime} 43^{\prime \prime}$ to $07^{\circ} 50^{\prime} 00^{\prime \prime} \mathrm{E}$. It has two seasons rainy seasons starts from April to October while dry season start from October to March.

\section{B. Sample Collection and Procedures}

Anopheles mosquitoes larval were collected from their natural water habitat in some communities of Nasarawa Local Government Area using Entomological ladles (i.e., plastic scoop to scooped) into a well labeled container, they were transported to the Insectary laboratory, Department of Zoology Nasarawa State University Keffi. The Anopheles larval were reared to adult stage in the laboratory and fed with biscuit and yeast while the adult fed on sugar solution according to the procedures of [24].

\section{Procedure for WHO Method of Susceptibility}

The susceptibility test was carried out using four bottles for each of the insecticides used (Bendiocarb and Deltamethrin) and two control bottles each. An aspirator was used to introduce 25 Anopheles mosquitoes into the coated bottles. A timer was used to record both the number of dead and live mosquitoes after 15 minutes to 30 minutes until all were dead. The mortality in the control bottle was recorded as well [24].

\section{Data Analysis}

The data was analyzed using Chi Square analysis to test the level of significance between the insecticides used in the study.

\section{RESULTS}

Result showed that a total number of 100 female Anopheles mosquitoes exposed to CDC bioassay bottle for 30 minutes and at 15 minutes $99 \%$ were knockdown and 1 alive and at 30 minutes observation, there was $100 \%$ knockdown/mortality of the adult Anopheles mosquitoes. At 30 mins there was no mortality recorded from the control (Table I). The result of the chi square analysis was statistically insignificant $(\mathrm{p}=0.199)$ since $\mathrm{p}>0.05$.

One hundred (100) adult Anopheles mosquitoes were exposed to Deltamethrin using CDC bioassay bottle for 30 minutes. Anopheles mosquitoes were observed for 15 minutes and 30 minutes, at 15 minutes 98\% Anopheles mosquitoes were knockdown while 2 were alive. At 30 minutes there was $100 \%$ knockdown/mortality of Anopheles mosquitoes after post exposure and no record of mortality from the control (Table II). The chi square analysis was statistically insignificant $(\mathrm{p}=0.199)$ since $\mathrm{p}>0.05$.

Total number of 100 adult Anopheles mosquitoes were exposed to Bendiocarb using WHO impregnated paper and mortality was recorded every 10 minutes for 60 minutes and 24 hour post exposure. At 60 minutes there was $100 \%$ knockdown of Anopheles mosquitoes, and the control was $0 \%$, but at $24 \mathrm{~h}$ post exposure, $2(1 \%)$ mortality was recorded from the control (Table III). The mortality of Anopheles mosquitoes to Bendiocarb was highly insignificant $(p=0.243)$.

A total number of 100 female Anopheles mosquitoes were exposed to Deltamethrin using WHO impregnated paper for 60 minutes and 24 hour post exposure. In Table IV, susceptibility was recorded at 60 minutes with $98 \%$ mortality of Anopheles mosquitoes. After 24h post exposure, $100 \%$ mortality was recorded, while $2(1 \%)$ mortality was observed from the control. Statistically there is no significant difference $p=0.224$.

TABLE I: SuscePtiBILITY OF ANOPHELES MOSQUITOES EXPOSED TO BENDIOCARB USING CDC

\begin{tabular}{cccccc}
\hline $\begin{array}{c}\text { Exposure } \\
\text { time } \\
(\text { mins })\end{array}$ & $\begin{array}{c}\text { Number of } \\
\text { An. } \\
\text { Mosquitoes } \\
\text { exposed }\end{array}$ & $\begin{array}{c}\text { Number } \\
\text { alive }\end{array}$ & $\begin{array}{c}\text { Number of } \\
\text { An. } \\
\text { Mosquitoes } \\
\text { knockdown }\end{array}$ & $\begin{array}{c}\% \\
\text { knockdown }\end{array}$ & $\begin{array}{c}\text { Control } \\
\text { R1 R2 }\end{array}$ \\
\hline 0 & 100 & 100 & 0 & 0 & 00 \\
15 & 100 & 2 & 98 & 98 & 00 \\
30 & 100 & 0 & 100 & 100 & 00 \\
\hline
\end{tabular}

TABLE II: SUSCEPTIBILITY STATUS OF ANOPHELES MOSQUITOES TO DELTAMETHRN USING CDC BIOASSAY BOTTLE

\begin{tabular}{cccccc}
\hline $\begin{array}{c}\text { Exposure } \\
\text { time } \\
(\text { mins })\end{array}$ & $\begin{array}{c}\text { Number of } \\
\text { An. } \\
\text { Mosquitoes } \\
\text { exposed }\end{array}$ & $\begin{array}{c}\text { Number } \\
\text { alive }\end{array}$ & $\begin{array}{c}\text { Number of } \\
\text { An. } \\
\text { Mosquitoes } \\
\text { knockdown }\end{array}$ & $\begin{array}{c}\% \\
\text { knockdown }\end{array}$ & $\begin{array}{c}\text { Control } \\
\text { R1 R2 }\end{array}$ \\
\hline 0 & 100 & 100 & 0 & 0 & 00 \\
15 & 100 & 2 & 98 & 98 & 00 \\
30 & 100 & 0 & 100 & 100 & 00 \\
\hline
\end{tabular}

TABLE III: SUSCEPTIBILITY STATUS OF ANOPHELES MOSQUITOES TO BENDIOCARB USING WHO IMPREGNATED PAPERS

\begin{tabular}{cccccc}
\hline $\begin{array}{c}\text { Exposure } \\
\text { time } \\
\text { (mins) }\end{array}$ & $\begin{array}{c}\text { Number of } \\
\text { An. } \\
\text { Mosquitoes } \\
\text { exposed }\end{array}$ & $\begin{array}{c}\text { Number of } \\
\text { An. } \\
\text { Mosquitoes } \\
\text { knockdown }\end{array}$ & $\begin{array}{c}\text { Number } \\
\text { alive }\end{array}$ & $\begin{array}{c}\% \\
\text { knockdown }\end{array}$ & $\begin{array}{c}\text { Control } \\
\text { R1 R2 }\end{array}$ \\
\hline 10 & 100 & 0 & 100 & 0 & 00 \\
20 & 100 & 40 & 60 & 40 & 00 \\
30 & 100 & 74 & 26 & 74 & 00 \\
40 & 100 & 96 & 4 & 96 & 00 \\
50 & 100 & 99 & 1 & 99 & 00 \\
60 & 100 & 100 & 0 & 100 & 00 \\
$24 \mathrm{~h}$ & 100 & 100 & 0 & 100 & 11 \\
\hline
\end{tabular}

TABLE IV: SUSCEPTIBLITY STATUS OF ANOPHELES MOSQUITOES EXPOSED TO DELTAMETHRIN USING WHO IMPREGNATED PAPERS

\begin{tabular}{cccccc}
\hline $\begin{array}{c}\text { Exposure } \\
\text { time } \\
(\text { mins })\end{array}$ & $\begin{array}{c}\text { Number of } \\
\text { An. } \\
\text { Mosquitoes } \\
\text { exposed }\end{array}$ & $\begin{array}{c}\text { Number of } \\
\text { An. } \\
\text { Mosquitoes } \\
\text { knockdown }\end{array}$ & $\begin{array}{c}\text { Number } \\
\text { alive }\end{array}$ & $\begin{array}{c}\% \\
\text { knockdown }\end{array}$ & $\begin{array}{c}\text { Control } \\
\text { R1 R2 }\end{array}$ \\
\hline 10 & 100 & 0 & 100 & 0 & 00 \\
20 & 100 & 21 & 79 & 21 & 00 \\
30 & 100 & 41 & 59 & 41 & 00 \\
40 & 100 & 68 & 32 & 68 & 00 \\
50 & 100 & 85 & 15 & 85 & 00 \\
60 & 100 & 98 & 2 & 98 & 00 \\
$24 \mathrm{~h}$ & 100 & 100 & 0 & 100 & 11 \\
\hline
\end{tabular}




\section{DISCUSSION}

Adult female Anopheles mosquitoes exposed to bendiocarb $12.5 \mathrm{mg}$ using CDC bioassay bottle for 30mins were $100 \%$ susceptible to the insecticide and $15 \mathrm{mins}$ with 99\% knockdown/mortality. [21] Observed that Anopheles stephensi were susceptible to CDC bioassay bottles of Bendiocarb at $97.5 \%$, [13] also observed that Anopheles gambiae, Anopheles funestus were $100 \%$ susceptible to Bendiocarb at $15 \mathrm{mins}$ of exposure in Uganda. This is because Bendiocarb work by inhibiting acetylcholesterase, enzymes required for nerve impulses leading to death of the mosquitoes.

Anopheles mosquitoes exposed to Deltamethrin were susceptible at 15 minutes of exposure with $98 \%$ knockdown/mortality while $100 \%$ knockdown/mortality was observed at 30 minutes. This is because Pyrethroid insecticides works by disrupting the nervous system of Anopheles mosquitoes by weakening the insect leading to death. These findings support [1] who observed Anopheles mosquitoes' susceptibility to Deltamethrin (100\%) mortality. [21] Also reported susceptibility of Anopheles mosquitoes to Deltamethrin using CDC bioassay bottle with $100 \%$ mortality in Iran. Though, this study is in contrast with the study of [13] who observed that Anopheles gambiae were resistance to Deltamethrin with only $87 \%$ mortality.

Anopheles mosquitoes exposed to WHO impregnated papers of Bendiocarb for $60 \mathrm{mins}$ indicated $100 \%$ mortality. [15] Also reported high susceptibility of Anopheles mosquitoes (100\%) in Anambra state. This study is also similar to the work done by [6] in Rivers state with (100\%) knockdown/mortality to Bendiocarb. Similarly, [3] reported susceptibility of Anopheles mosquitoes to Bendiocarb in Akwa Ibom state with 99\%-100\% mortality. Though, [10] reported resistance of Anopheles mosquitoes to Bendiocarb in Ibadan with only $87.7 \%$ knockdown/mortality. While [20] observed high resistance of Anopheles spp to Bendiocarb in Bauchi (17.29\%) mortality. [16] observed total resistance of Anopheles mosquitoes to Bendiocarb (80\%) in Lagos. This may probably be due to climate change which can influence the shift of variance where there is susceptibility and in another it shows resistance to Bendiocarb.

The female Anopheles mosquitoes exposed to Deltamethrin using WHO impregnated papers were susceptible at 60 minutes with $98 \%$ mortality which is in agreement with WHO standard of susceptibility. This study confirmed the findings in Ibadan by [10] where Anopheles mosquitoes were susceptible to Deltamethrin (98.8\%) mortality. Though [6] observed resistance of Anopheles mosquitoes to Deltamethrin (25-65\%) mortality. [20] Also recorded resistance of Anopheles mosquitoes to Deltamethrin in Bauchi state (13.20\%) mortality [3]. Also observed resistance of Anopheles mosquitoes to Deltamethrin in Akwa Ibom state (63-66\%) mortality. These variations may be due to differences in environmental conditions affecting the Anopheles mosquitoes.

\section{CONCLUSION}

From this present study, Anopheles mosquitoes were susceptible to Deltamethrin and Bendiocard. From the result, CDC bioassay bottle and WHO impregnated papers method of susceptibility adherence to protocol and procedure of WHO standard were followed and a knockdown/mortality was observed at a standard approved state of mortality of Anopheles mosquitoes in the areas of samples collected. Therefore, Deltamethrin and Bendiocarb are active insecticides which should be recommended for control of mosquitoes and could be used as one of the intervention national malaria vector control programme.

\section{ACKNOWLEDGEMENT}

Our sincere gratitude goes to the Staff of WHO insect laboratory of the department of Zoology, Nasarawa State University Keffi for their support throughout the work.

\section{REFERENCES}

[1] Aizoun, N, Osse, R., Azoundekon, R., Alia, R., Oussou, O., Gnanguenon, V., Aikpon, R., Paidonou, G., and Akogbeto M., (2013). Comparison of the standard WHO susceptibility tests and the CDC bottle bioassay for the determination of insecticides susceptibility in malaria vectors and their correlation with biochemical and molecular biology assay in Benin west Africa. http://www.parasite and vectors 6:147.

[2] Atoyebi S. M, Tchigossou G. M, Akoton R, Riveron M. J, Irving H, Weedall G, Tossou E, Djegbe I, Oyewole I. O, Bakare A.A, Wondji C. $\mathrm{S}$ and Djouaka R., (2020). Investigating the molecular basis of multiple insecticides resistance in a major malaria vector Anopheles funestus (sensu stricto) from Akaka-Remo, Ogun State, Nigeria. Parasites and vectors. https: //doi.org/10.1186/s13071-020-04296-8. (13):423.

[3] Atting, I. A., Ekpo, N. D., Akpan, M. E., Bassey, B. E., Asuquo, M. J., Usip, L. P. E., Inyan, P. U. and Samdi, L. M. (2019): Insecticides susceptibility profile of malaria vector population from the coastal and mainland areas of Akwa Ibom state, Nigeria. Journal of advances in medicine and medical research 29 (7): 1-11: Article no JAMMR 48612.

[4] Balarabe, R. M, Yayo, M. A., and Yusuf, Y. D (2015). Insecticides resistance to Anopheles spp. Mosquitoes (Diptera: culicidae) in Nigeria: A review. International Journal of Mosquito Research, 2 (3); 56-63.

[5] Djouaka R. J, Atoyebi S. M, Tchigossou G. M, Riveron J. M, Irving H, Akoton R (2016). Evidence of a multiple insecticide resistance in the malaria vector Anopheles funestus in South West Nigeria. Malaria Journal (15):565.

[6] Ebere N., Atting I., Ekerette I., and Nioking, (2019): Assessment of level of susceptibility of Anopheles gambiae s.l to public health insecticides in a malaria vector sentinel site, Rivers state, Nigeria. Annual Research and Review in Biology 32 (1): 1-10. Article no ARRB. 46056 ISSN:2347-565X, NLMID:101632869.

[7] FMOH/NMCP (2009): Federal Republic of Nigeria training manual for management of malaria in Nigeria Participants' Manual Federal Ministry of Health National Malaria and vector Control Division, Abuja-Nigeria:1-86.

[8] Habibu, U. A, Yayo, A. M and Yusuf, Y. D (2017): Susceptibility of Anopheles gambiae complex to insecticides commonly used for malaria control in Northern Nigeria International Journal of science and technology (6): ISSN 2277-8616

[9] Hakizima E, Karema C, Munyakanage D, Iranzi G, Githure J, Tongren J. E, Takken W, Binagwaho, A and Koenraadt C. J. M. (2016) Susceptibility of Anopheles gambiae to insecticides used for malaria vector control in Rwanda. Malaria journal. 15:582. Doi 10.1186/s12936-016-1618-6.

[10] Kolade, T. I, Kehinde, O. P, Oluwatobi, R. A, Adedapo, O. A, and Audu, K. O., (2013): Susceptibility of Anopheles gambiae sensu lato (Diptera: Culicidae) to Permethrin, Deltamethrin and Bendiocarb in Ibadan city, southwest Nigeria. Current Research Journal of Biological Sciences 5(2): 42-48. 
[11] Martha, B, Musa, J and Awolola, T. S (2009): Status of insecticdes susceptibility in Anopheles gambiae s.l from malaria surveillance sites in The Gambia. Malaria Journal 8:187 doi:10.1186/1475-2875-8-187.

[12] Massuod, W. A. M., Raqib, S. M., Budiharjo, A and Mahajoena, E., (2014). Larvicidal Potentiality of the bandotan (AgeratumConyzoides) Leaves for Controlling the Three Important Species of Mosquitoes (Aedes Aegypti, Culex Quinquefasciatus and Anopheles Maculatus). IJCBS, 1(6).

[13] Michael, O., David. F. H., James, K., John, B. R., Betty, M., Dennis, A., Ananya, P., David, W. O., Albert, P. O. and John, G. (2018): Insecticide resistance status of malaria mosquitoes in Uganda: Malaria Journal 17:157.

[14] NMCP (National Malaria Control Program) (2014): Official Website. www.nmcp, gov.ng 10-11.

[15] Nwankwon, E. N, Okorie. P. N, Acha, C. T, Okonkwo, O. E, Nwangwu, U. C and Ezihe, E. K, (2017): Insecticide Resistance in anopheles gambiae s.l mosquitoes in Awka Anambra state, southeast Nigeria. Journal of mosquito Research, 7(5):32-38.

[16] Oduola, A. O, Idowu, E. T, Oyeebola, M. K., Adeogun, A. O, Olojede, J. B, Otubanjo., O. A, and Awolola, T. S., (2012): Evidence of carbamate resistance in urban population of Anoheles gambiae ss. Mosquitoes resistance to DDT and deltamethrin insecticide in Lagos, South-Western Nigeria, Parasite Vectors. 5:116. doc:10.1186/17563306-5-116.

[17] Okorie, P. N, Mckenzie, F.E, Ademowo, O. G, Bockarie, M and Louise K (2011): Nigeria Anopheles vector Database: An Overview of 100 years research. Plosone.66 (12):1-16. Doi:10.1371/journal. pone 0028347. Source:Public Medical.

[18] Opara, K. N, Ekanem, M. S, Udoiding, N. I, Chikezie, F. M, Akro, G, Usip, L. P, Oboho, D. E. and Igbe, M. A. (2017): Annual Research and Review in Biology 18(4):1-9; Article no.ARRB.3588 ISSN:2347565X,NLID: 101632869.

[19] Rivero, A, Vezilier, J, Weill, M, Read, A.F and Gandon, S. (2010): Insecticide Control of Vector-Borne Disease: When is Insecticide Resistance a Problem? Plos Pathogens 6(8): e1001000. doi:10.1371

[20] Umar, A, Kabir, B. G. J, Amajoh, C. N., Inyama, P. U., Ordu, D. A., Barde, A. N., Misau, A. A., Sambo, M. L., Babuga, U., Kobi, M. and Jabbdo, M. A. (2014): Susceptibility test of female Anopheles mosquitoes to ten insecticides for indoor residual spraying (IRS) baseline data collection in Northeastern Nigeria. Journal of Entomology and Nematology 6(7):98-103.

[21] Vatandoost H., Abai, M. R., Akbari, M., Reeisi, A., Yousefi, H., Sheikh S., Bagheri, A (2019): Comparison of CDC bottle bioassay with WHO standard method for assessment susceptibility level of malaria vector, Anopheles stephensis to three imagicides $\mathrm{n}$ Tehran, Iran. Journal of Arthropods- Borne Diseases, 13 (1): 17-26.

[22] WHO (2016). World malaria report; World Health Organization Geneva: https //www.who.int/malaria/media /world -malaria-report/en/.

[23] WHO (2010): World Malaria Report World Health Organization, Geneva. https //www.who.int/malaria/media /world -malaria - report/en/.

[24] WHO (1998): Test procedures for insecticides resistance in malaria vectors, Bio-efficacy and persistence of insecticides on treated surfaces. WHO/ CDS/CPC/Ma journal 12: 98. 